\title{
Small Hydro Plant Developments
}

\author{
Dr. Péter Kádár, member of IEEE \\ Óbuda University \\ Dept. of Power Systems \\ Bécsi u. 94. Budapest H-1034 HUNGARY \\ Phone: +36 209447 241; fax: +30 1250 0940; e-mail: kadar.peter@kvk.uni-obuda.hu
}

\begin{abstract}
The exploitation of the renewable sources is a challenge for all the engineers. Hydro power application is ranging from a $\mathrm{kW}$ to order of GW. The technical solutions have a wide spectra, such as turbines and dam constructions. The hydro power potential of Hungary is modest. Óbuda University cooperates with the patent owner in the development of new devices. In this paper we introduce the latest development for the mini hydro applications capable of deploying low heading watercourses and small size rivers. The fast mountable flowing through arrangement and the anchored floating Sagebien wheel devices have $5-10 \mathrm{~kW}$ output power. These days the operations are in the test phase.
\end{abstract}

\section{Key words}

mini hydro plants, low headings, floating plant, $\mathrm{R}+\mathrm{D}$

\section{Hydro power in Hungary}

In the last decade there were a lot of plans made for developing the Hungarian hydro plant capacity.

The possibilities are really limited because of the low hydro potential. Present day Hungary is a flat land with a huge amount of water and lack of falls. There are a lot of environment protection constraints, too. The main aspects of the developments are:

- $\quad$ small environmental disturbances

- low cost

- $\quad$ frequent floods

- $\quad$ small falls

- $\quad$ fast construction/mounting

\section{Mounted small dam}

The concept of the dam is: easily mountable traversal dam with low heading. It can be put in operation or be removed in one hour before and after the rise of the tide.

\section{Construction}

The creek bed is padded by concrete. Fixing slots and points are preconceived.
Setting

The elements are deposed outside the floodplain (iron dam, turbine). These are transported to the site and craned to its location.

Operation

Continuous energy production $(0,4 \mathrm{kV} ; 3-10$ $\mathrm{kW}$ ), without control

Maintenance

Inspection, lubrication may be done in operational position. Anticorrosion painting can be done on the bank.

Flood icy flood

In case of a forecasted flood the elements can be removed in 1 hour. If the dam is left in its original position, the flood tumbles over it.

The solution is recommended to streams with small heading $(1-2,5 \mathrm{~m})$

low runoff $\left(0,3-2 \mathrm{~m}^{3} / \mathrm{s}\right)$

medium width $(3-8 \mathrm{~m})$

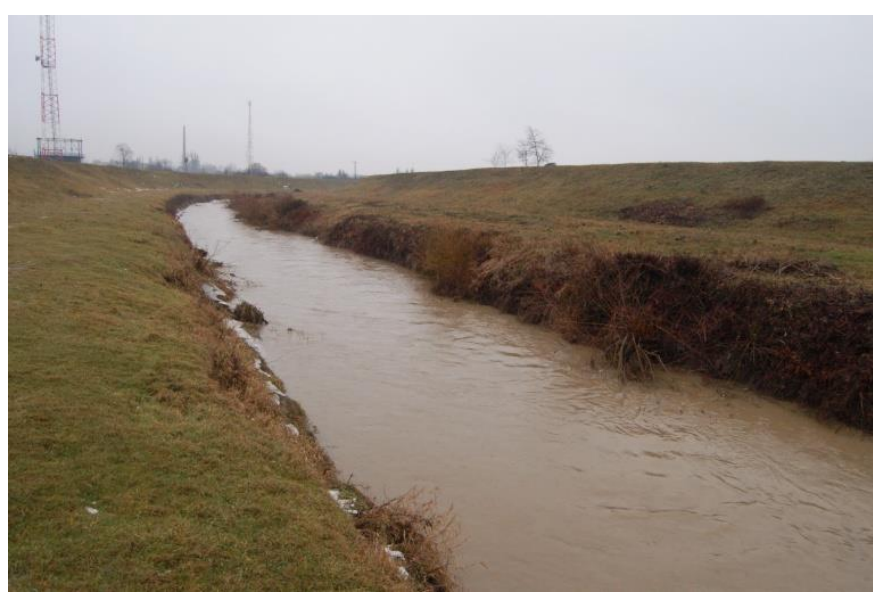

Fig. 1. A possible deployment site 


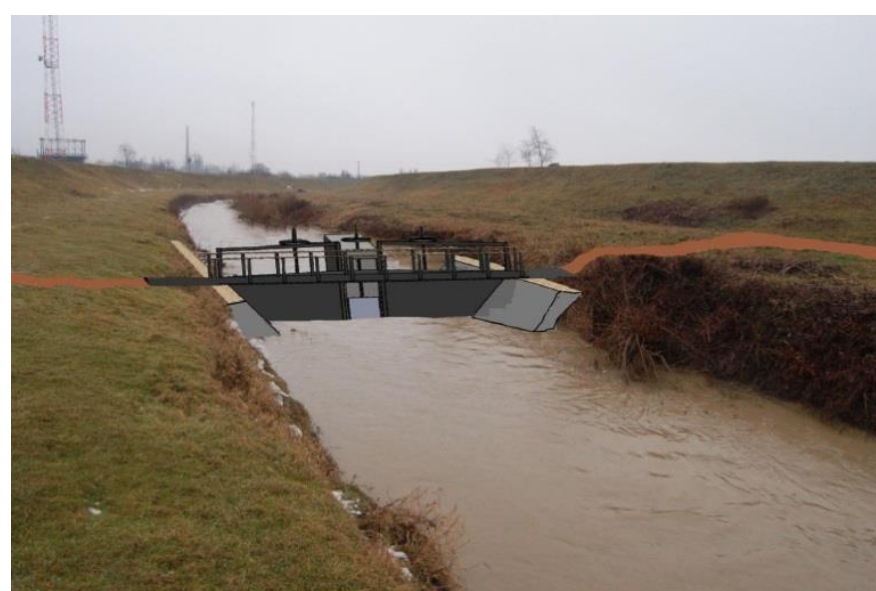

Fig. 2. The plan of the mounted dam

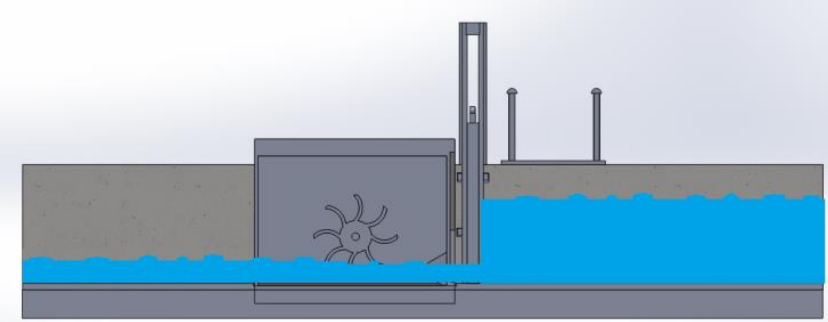

Fig. 3. Mounted dam with undershot waterwheel

The system can be mounted by undershot or overshot waterwheel or pipe turbine. Now the work is going on some feasibility studies for different deployment sites.

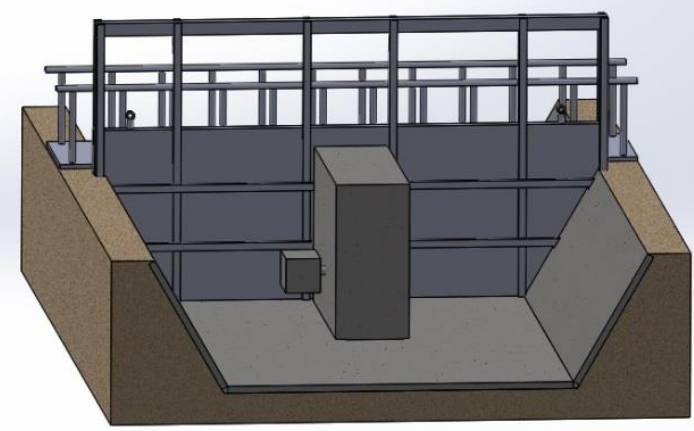

Fig. 4. Thumbnail image of the assembled dam

\section{Anchored pontoon plants}

As the renaissance of the Sagebien-type watermill, some experiments are made with floated pontoon solutions.

If the stream is wider than $10 \mathrm{~m}$ and the flood level is really volatile the cross dam solution is a really large intervention in the environment.

The pontoon can be anchored in the main stream but can be supported by kickstand to the bank. It works as a bridge to the hull too.

The torque is made of the $6 \mathrm{~m}$ wide waterwheel propelled by the stream. The 3 times 12 paddles are mounted on a drum, having relative $30^{\circ}$ offset.
The mechanical rotation is trained by spurwheels and belts. It is geared up from $6 \mathrm{rpm}$ to $1000 / 1500 \mathrm{rpm}$. The nominal power of the double fed induction generator is 10 $\mathrm{kW}$ on $0,4 \mathrm{kV}$.

The hull, the other parts are made of welded iron, the floating drums are made of plastic.

The only facilities on the bank are the cleats and the electrical cable connection point.

\section{A. Serial No.001}

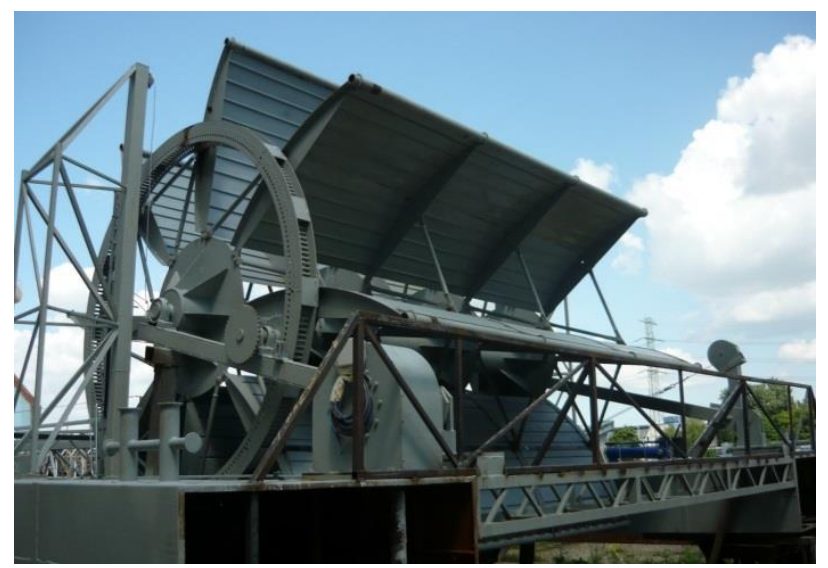

Fig. 5. Floating pontoon Serial No. 001

The first unit was tested by pushing and pulling by an external ship in still water harbor. Based on the experiences gathered, the next version was redesigned: wider paddles, larger diameter, more stable hull.

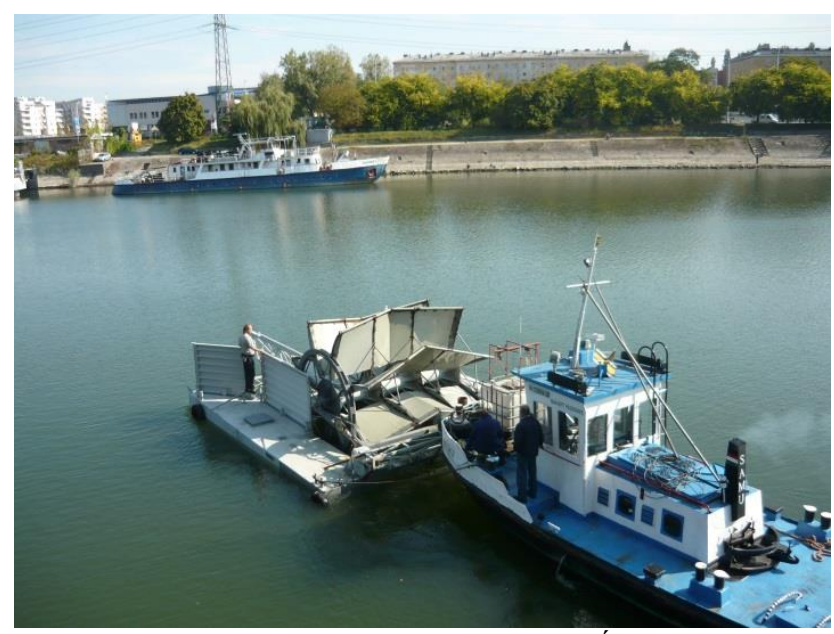

Fig. 6. Tests of Serial No. 001 at Danube port Újpest, Hungary

\section{B. Serial No.002}

This machine was transported to the bank of the wide river Danube. Unfortunately at the installation site large logs often got nipped and the flow conditions weren't favorable. 


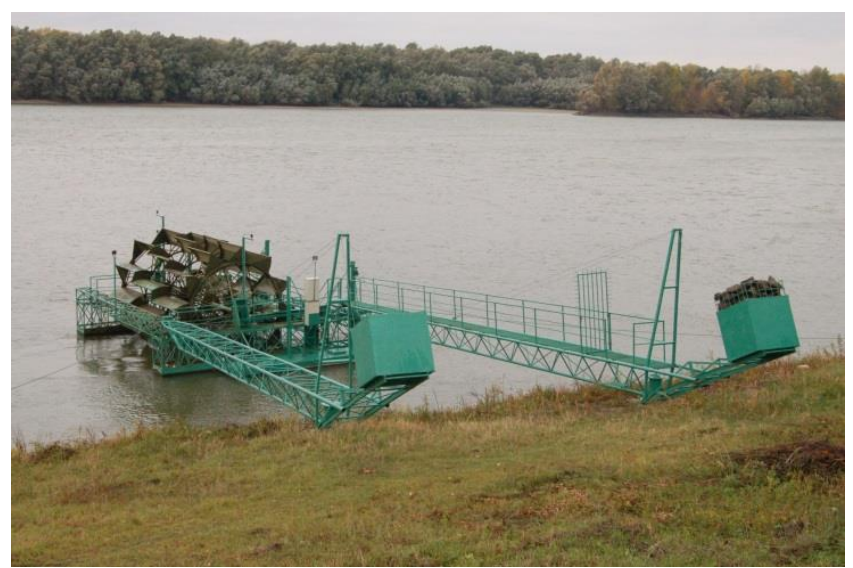

Fig. 7. In operation Serial No. 002 at Danube at Harta, Hungary

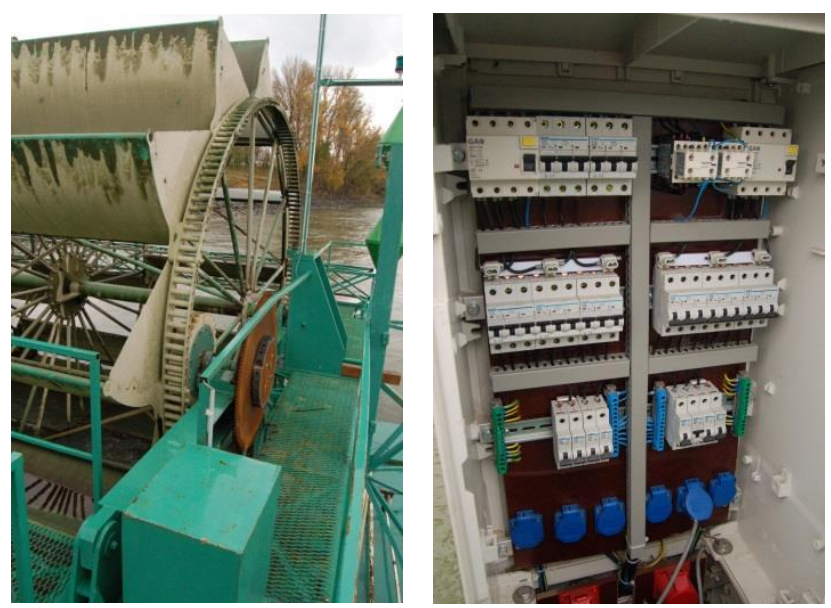

Fig. 8. Gear and electric connection box of Serial No. 002

\section{Serial No.003}

The new Serial No. 003 was implemented in year 2012 and came into test operation in 2013 at the Hungarian Croatian border-line river called Mura. The system works in island mode and the network connection is under construction. The necessary accessories are under consideration, as external waterway barrier and trash rack.

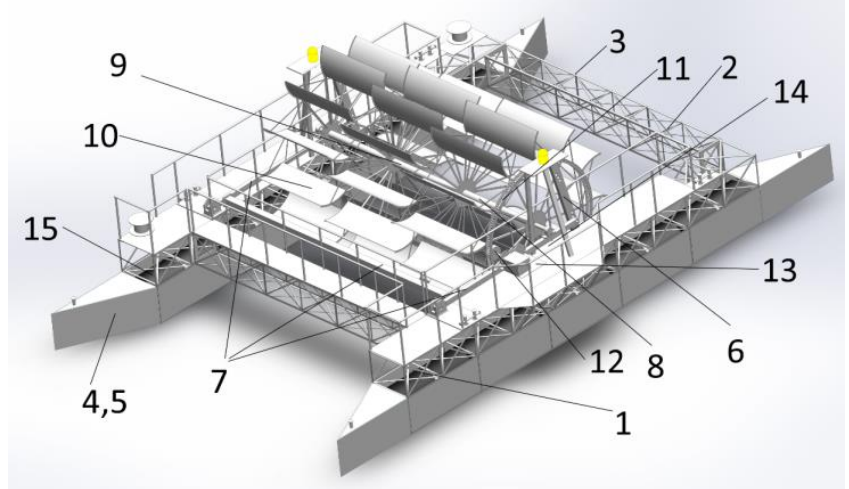

Fig. 9. Main elements of Serial No. 003

The system has the main elements

1 fore-and-aft hull

2,3 cross hull

4,5 diffusor
6 tripod

$7 \quad$ U shape holder

8,9 shaft

10 paddle

11 freewheel

12 cogwheel of the generator

13 generator fixing base

14 lifting tower

15 floating barrels

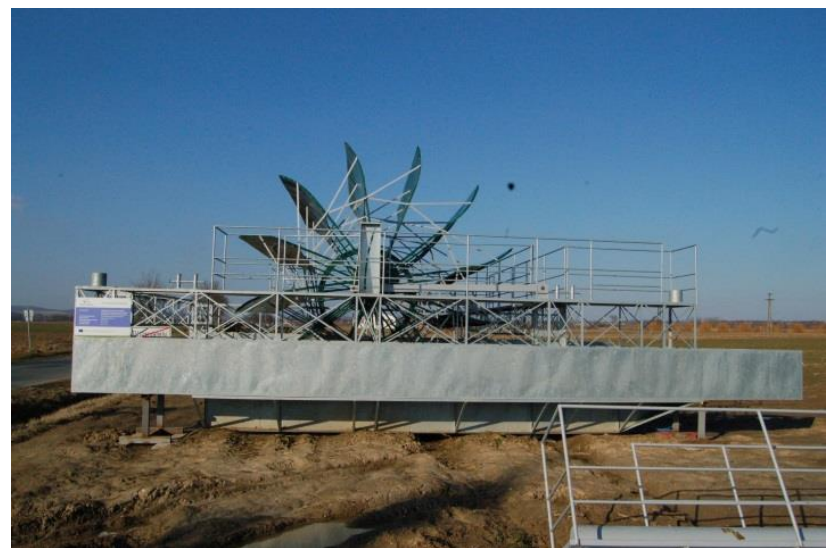

Fig. 10. Serial No. 003 in dry dock

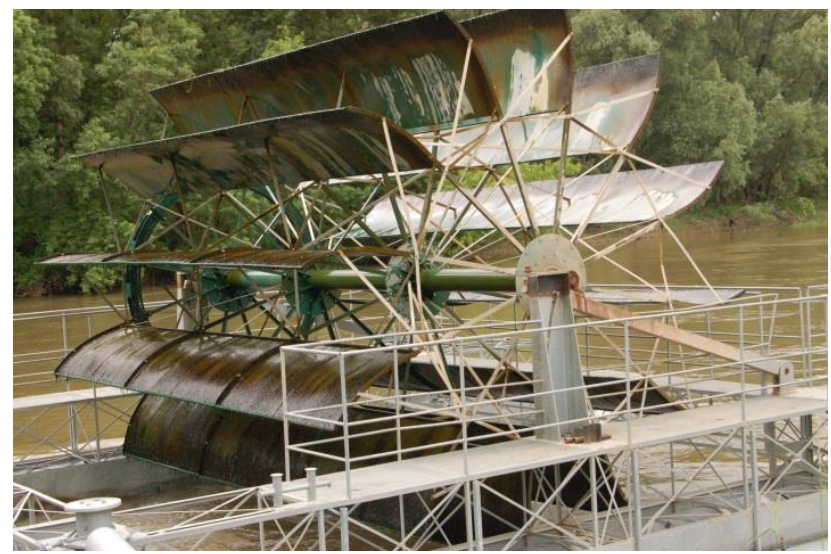

Fig. 11. Serial No. 003 in operation at river Mura, Hungary

\section{Test experiences}

There are several ways to calculate the power output of water wheels [8]. The most widely used equation is based on the impulse change of the water:

where

$$
\mathrm{P}=\rho * \mathrm{~b} * \mathrm{a} * \mathrm{v} * \mathrm{u} *(\mathrm{v}-\mathrm{u}) * \eta
$$

$$
\begin{aligned}
& \mathrm{P}=\text { mechanical power output }[\mathrm{kW}] \\
& \rho=\text { density of the flowing liquid }\left[1000 \mathrm{~kg} / \mathrm{m}^{3}\right] \\
& \mathrm{b}=\text { heights of the paddle }[1 \mathrm{~m}] \\
& \mathrm{a}=\text { width of the paddle }[6 \mathrm{~m}] \\
& \mathrm{v}=\text { river speed }[2 \mathrm{~m} / \mathrm{s}] \\
& \mathrm{u}=\text { relative paddle speed }[1 \mathrm{~m} / \mathrm{s}] \\
& \eta=\text { efficiency }
\end{aligned}
$$

Putting the actual values into the equation we get $12 \mathrm{~kW}$ as maximal power output.

The mechanical torque measurement was performed by a Prony brake by Mr. Endre Szabó. 
The measured maximum power was $6,2 \mathrm{~kW}$ at $30 \mathrm{rpm}$. The efficiency is 0,51 . It could be improved by the increase of the diameter of the waterwheel, changing the cut-in-the-water-angle of the paddles and by a special controlled-angle-paddle wheel. The electrical measurements verified the mechanical experiences.

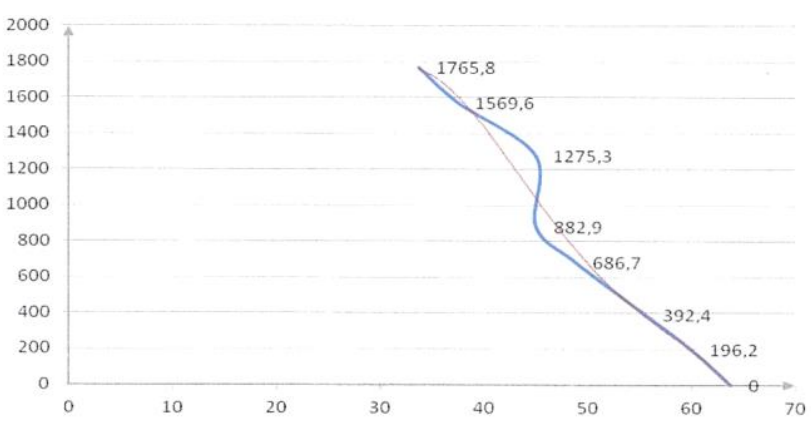

Fig. 12. Torque (Nm) vs. speed (rpm) measurement
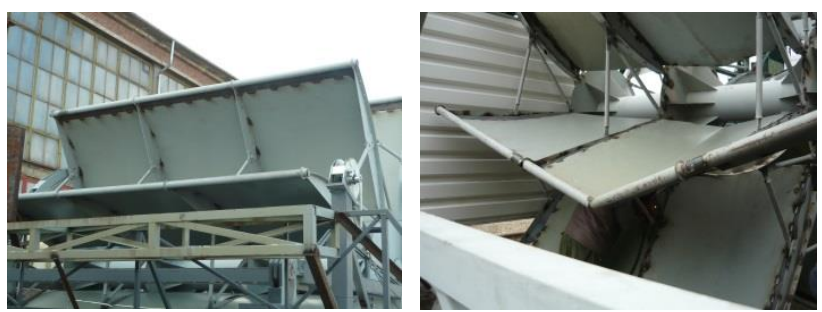

Fig. 13. Straight and "shark tooth" paddle edges

Some experiments were performed about the paddle edges. The process of the cut-in-the-water and cut-off-thewater was investigated at different shapes:

straight edge

"shark tooth"

splitted-shifted

small teeth.

There are still some areas for potential development. These are

passing floating logs, trash - the machine should be prepared for interaction with an unforeseeable floater

stand against fluctuation - the high waves exercise continuous dynamic load

behavior in a frozen environment - the water drops can easily freeze and huge ballasts get formed

resist floating ice - the best solution could be an external waterway barrier drawing off the ice flow. By the way the floating iron construction and the water-wheel should be protected from "ice crash".

The construction is tied up to the bank by wire ropes and shoulder rods. It allows for the change of the river level. The system has not been tested in a frozen environment.

The electricity is harvested at a $10 \mathrm{~kW} / 12,5 \mathrm{kVA}$ Leroy type alternator at $400 \mathrm{~V} ; 3$ phase $\mathrm{AC} ; 1500 \mathrm{rpm}$.

\section{Conclusion}

There are more hydro plant solutions offered for low speed narrow rivers. The first test measurements of the floating plant are promising. Now we are tuning the details and setting the power point to maximum. Based on the prototype we expect standardized production.

\section{Acknowledgement}

We thank patent owner Gábor Fontány and company Aquaenergia for the cooperation. Special thanks to Rita Fontány, János Süli and Endre Szabó. Thanks student Imre Ress for the participation in the project. The project serial No.3. "Renewable energy sources for WWTP Totszerdahely" was funded by Hungary-Croatia IPA Cross-border Co-operation Programme No. HUHR/1001/1.1.2/0004 'SMART WWTPs' Renewable energy sources for WWTP Totszerdahely and Main project for WWTP Donja Dubrava - technical documentation - Local Government of Tótszerdahely.

\section{References}

[1] A guide to UK mini-hydro developments; The British Hydropower Association, 2005

[2] L. Föczény: Micro pumped storage hydro plant, F\&L Ltd., 2010

[3] P. Kadar: From watermill till hydro plants; New mandate publ. Budapest, 2010

[4] European Renewable Energy Council - Second edition (EREC), (2010): Renewable Energy in Europe, Markets, trends and technologies Earthscan Ltd, Dunstan House, 14a St Cross Street, London

[5] P. Kadar: The Climate Change and the Power Industry; chapter in book Climate Change - Research and Technology for Adaptation and Mitigation ISBN 978-953307-621-8; Edited by: Juan Blanco; Publisher: InTech, September 2011

[6] G. Fontany: Floating hydro plant, 2012

[7] Central and Eastern European Hydro Power Outlook KPMG 2012

[8] András Ouirin: Application of mill structures; fenntarthato.hu/epites/Members/andrasq/hajomalom.docx 